\title{
Genetic determinants of survival
}

\author{
HUGH MONTGOMERY
}

Corresponding author:

Institution for Sport, Exercise and Health

University College London

1st floor, 170 Tottenham Court Road

London W1T 7HA, United Kingdom

Phone: 0044 (0)7500335756

E-mail: h.montgomery@ucl.ac.uk

\section{ABSTRACT}

The human genome comprises some 20,000 genes, or 3 billion base pairs. Variation in this genetic sequence is common and some of these variants affect gene function or the protein transcribed from it. Human characteristics are determined by the interaction of the genome with environmental challenges, and differences between us thus result from variation in those challenges and in the genome itself. This is true of human susceptibility to disease, and survival from it. Genetic variation influences human behaviours which may predispose to health or disease; the risk of contracting an infectious disease, or of suffering diseases such as cancer or myocardial infarction; the development of complications; the response to any treatment administered; and thus the outcome of the disease state. Genetic studies can help shed light on the mechanisms which underpin disease processes, whilst perhaps suggesting ways in which treatment might be 'personalised', and novel therapeutic targets for drug development.

More sophisticated approaches to such endeavours are required, given the failure to identify the bulk of gene variants of influence using conventional strategies.

Key words: gene, polymorphism, survival, genome

The human genome comprises some 20,000 genes, themselves composed of 3 billion pairs of bases. It is this shared and common inheritance which defines our species and makes us all human. However, significant variation occurs within this genome. There are some 38 million sites of common variation, of which 15 million sites exhibit a variant in $>1 \%$ of cases. Overall then, whilst any two humans are genetically $99.9 \%$ similar, any individual is likely to differ from the human consensus genome at about 3 million sites. (1) Such variation can take many forms and any which occurs at a frequency of $>1 \%$ is termed a 'polymorphism'. At its simplest, a single 'letter' in the genetic sequence may be changed. If such a variation occurs at a frequency of $>1 \%$, then it is referred to as a single nucleotide polymorphism- or 'SNP'. Short Tandem Repeats (STRs) are 1-5 base pair (bp) repetitive sequences, and 'Variable Number Tandem Repeats' (VNTRs) are 5-64bp long repeats which can extend over thousands of base pairs. 'Copy Number Variants' (CNVs) occur when whole blocks of a gene are deleted, duplicated or inverted. At the other end of the spectrum, entire arms of chromosomes can be inverted, or chromosomes duplicated. (2)

Such variants may have no biological effect at all. However, others can affect human form and function. Most SNPs are 'silent' being sited outside coding regions and having no effect on gene expression. However, they may also be found in areas of the gene which effect its expression, or may alter its splicing. Those found in the coding region may affect the amino-acid sequence for which the gene encodes (they are 'non-synonymous') by either altering an amino acid (a 'missense' variant) or by causing a premature 'stop' in translation (a 'nonsense' variant). They may also affect splicing.

Whilst some diseases are entirely due to the presence of a rare gene variant, this is usually not the case: most human characteristics (or phenotypes) result from the interaction of an individual's genome with the environment to which it is exposed. Inter-individual differences in human phenotype thus result from differences in environmental exposures interacting with differences in genome sequence. In general, upwards of $25 \%$ of the variation in any human trait is due to genetic variation- and it can be much more. Some $45 \%$ of the variation in human height can thus be accounted for by genetic variation. (3)

Human susceptibility to disease is thus profoundly influenced by the genetic variants we inherit, as is the outcome from such disease states. Analysis of data relating to nearly 10,000 births from two villages between 1650 and 1927 shows longevity to be highly heritable. (4) Indeed, some $25 \%$ of the variation in human life expectancy being accounted for by genetic variation. (5) These influences are stronger, the older one becomes (perhaps due to a restriction in environmental challenges). Few if any loci have been identified which are proven to exert strong effect, although the sex chromosomes themselves appear to influence human longevity, with late survival (life expectancy on reaching the age of 50 years) in studies of historical datasets from France suggesting greater heritability for daughters than sons. (6)

Such influences on survival are not merely due to impacts on factors which all clinicians would identify as the risk of myocardial infarction, for instance. Sorensen and colleagues followed 960 families with children born from 1924-26 who were then adopted by unrelated individuals. Risk of death aged 16-58 was determined. In keeping with the heritability of longevity, the relative risk of death was 1.7 if a biological parent had died before the age of 50 years. Relative risk of the same cause of death was 1.19 for cancer, 4.5 for cardiovascular and cerebrovascular disease and 5.8 where death was due to infection. (7)

Genetic variation can interact at every level in determining survival. Some $46 \%$ of 
the variation in female participation in recreational exercise is determined by genetic variation, with perhaps as much as $68 \%$ of that in males being accounted for in this way. (8) A Genome-Wide study of leisuretime exercise in 978 European-ancestry American and 1644 unrelated Dutch adults revealed 37 SNPs associated with exercise participation. (9) Such a genetic influence might improve survival (through reduced cardiovascular risk) or increase it, if such participation is related to engagement in 'risky' sports or other behaviours. Such a propensity to take risk may in itself also be genetically influenced. Between 30\% and $60 \%$ of the variation in susceptibility to addictive diseases has a genetic origin- with some specific variants being associated with addiction to specific drugs (reviewed in (10)). Some of this appears attributable to genetic variants which are associated with novelty-seeking, thrill-seeking or risk-taking, as well as to addiction to any activity found pleasurable. Likewise, the 'stress response' to challenging situations may also be partly genetically-determined. (10)

Genetic variation can influence the response to drugs in a number of wayswhether through altered pharmacokinetics or pharmacodynamics, or altered cellular activity (e.g. those with two defective CYP2D6 alleles who are administered tamoxifen for breast cancer have much lower levels of the active metabolite endoxifen, and thus respond less well, whilst patients carrying two rare CYP2D6 alleles can't break down codeine to yield morphine). Indeed, some 20 gene loci affecting 80 or more medications have been identified to date which might find clinical application in medical practice. (11)

Other genetic variants can influence the chance of contracting an infectious disease once exposed. Indeed, by way of exemplar, genetic variation strongly influences sus- ceptibility to HIV-1 infection. (12) However, a genome-wide association study (GWAS) of patients with haemophilia A who received potentially-contaminated infusions of human factor VIII between 1977 and 1984 (before viral inactivation was introduced) failed to identify associated genetic variants, however. (13) Others have similarly failed- and such failure is not unusual in other scenarios. Thus, whilst some $45 \%$ of variation in human height is due to genetic factors, only $5 \%$ of this variation can currently be accounted for by known genetic variants. (3) This is likely because many genes each exert a small influence, because gene variants interact in complex and non-additive ways to influence risk, and because genome-wide studies (usually across $>1$ million genetic sites) require a statistical stringency which means that many variants of influence do not reach statistical significance in association.

It might thus appear impossible to identify genetic variants which might influence outcome from complex disease states such as those identified on the Intensive Care Unit (ICU). However, such influences are recognised- and some loci identified. Thus, angiotensin-1 converting enzyme (ACE) plays a pivotal role in the human circulating and tissue rennin-angiotensin systems, yielding biologically-active angiotensin II from (inert) angiotensin I, whilst degrading kinins. A common genetic variant exists in this gene, the absence (deletion, D allele) rather than the presence (Insertion, I allele) of a 287 base pair sequence being associated with higher circulating (14) and tissue $(15,16)$ ACE activity. ACE appears to play a role in the regulation of tissue metabolic and inflammatory responses, as well as to the response to hypoxia- the I-allele being associated with improved performance in the hypoxic environment associated with high altitude (reviewed in (17)). Perhaps because of such effects, the $\mathrm{D}$-allele has been associated with impaired outcome from meningococcal infection in children. (18) Inheritance of two D-alleles is associated with an up to 5-fold increased mortality from acute respiratory distress syndrome in adults when compared to those with two 'I'-alleles. (19-21) Such risk may extend to a risk of developing nosocomial pneumonia. (22) Meanwhile, the large-scale and multinational GenoSept study has identified a common variation in the FER gene which is associated with survival (or mortality) from sepsis in the context of pneumonia. The presence of each $\mathrm{C}$ (rather than $\mathrm{T}$ ) base being associated with reduced mortality when adjusted for age, with mortality being 9.5\%, 15.2\% and $25.3 \%$ for those of CC, CT and TT genotype respectively. (23)

In summary, then, genetic variation strongly influences human behaviours which may predispose to health or disease; the risk of contracting an infectious disease, or of suffering diseases such as cancer or myocardial infarction; the development of complications; the response to any treatment administered; and thus the outcome of the disease state. Genetic studies can help shed light on the mechanisms which underpin disease processes, whilst perhaps suggesting ways in which treatment might be 'personalised', and novel therapeutic targets for drug development. However, more sophisticated approaches to such endeavours are required, given the failure to identify the bulk of gene variants of influence using conventional strategies.

\section{ACKNOWLEDGEMENTS}

The author is partly funded by the University College London Hospitals NHS Trust / University College London (UCLH/UCL) NIHR Comprehensive Biomedical Research Centre.

\section{REFERENCES}

1. Sudmant PH, Rausch T, Gardner EJ, Handsaker RE, Abyzov A, Huddleston J, et al. An integrated map of structural variation in 2,504 human genomes. Nature [Research Support, N.I.H., Extramural Research Support, Non-U.S. Gov't] 2015 Oct 1;526(7571):75-81.

2. Pollex RL, Hegele RA. Copy number variation in the human genome and its implications for cardiovascular disease. Circulation [Research Support, Non-U.S. Gov’t Review] 2007 Jun 19;115(24):3130-8.

3. Yang J, Benyamin B, McEvoy BP, Gordon S, Henders AK, Nyholt DR, et al. Common SNPs explain a large proportion of the heritability for human height. Nat Genet [Research Support, N.I.H., Extramural Research Support, Non-U.S. Gov't] 2010 Jul;42(7):565-9.

4. Kemkes-Grottenthaler A. Parental effects on offspring longevity-evidence from 17th to 19th century reproductive histories. Ann Hum Biol 2004 Mar-Apr;31(2):139-58. 
5. Brooks-Wilson AR. Genetics of healthy aging and longevity. Hum Genet 2013 Dec;132(12):1323-38.

6. Cournil A, Legay JM, Schachter F. Evidence of sex-linked effects on the inheritance of human longevity: a population-based study in the Valserine valley (French Jura), 18-20th centuries. Proc Biol Sci 2000 May 22;267(1447):1021-5.

7. Sorensen TI, Nielsen GG, Andersen PK, Teasdale TW. Genetic and environmental influences on premature death in adult adoptees. N Engl J Med [Research Support, Non-U.S. Gov’t] 1988 Mar 24;318(12):727-32.

8. De Moor MH, Posthuma D, Hottenga JJ, Willemsen G, Boomsma DI, De Geus EJ. Genome-wide linkage scan for exercise participation in Dutch sibling pairs. Eur J Hum Genet [Research Support, Non-U.S. Gov't] 2007 Dec;15(12):1252-9.

9. De Moor MH, Liu YJ, Boomsma DI, Li J, Hamilton JJ, Hottenga JJ, et al. Genome-wide association study of exercise behavior in Dutch and American adults. Med Sci Sports Exerc [Research Support, N.I.H., Extramural Research Support, Non-U.S. Gov't] 2009 Oct;41(10):1887-95.

10. Kreek MJ, Nielsen DA, Butelman ER, LaForge KS. Genetic influences on impulsivity, risk taking, stress responsivity and vulnerability to drug abuse and addiction. Nat Neurosci [Research Support, N.I.H., ExtramuralResearch Support, Non-U.S. Gov’t Review] 2005 Nov;8(11):1450-7.

11. Relling MV, Evans WE. Pharmacogenomics in the clinic. Nature [Research Support, N.I.H., Extramural Research Support, Non-U.S. Gov't Review] 2015 Oct 15;526(7573):343-50.

12. Biasin M, De Luca M, Gnudi F, Clerici M. The genetic basis of resistance to HIV infection and disease progression. Expert Rev Clin Immunol [Research Support, Non-U.S. Gov’t Review] 2013 Apr;9(4):319-34.

13. Lane J, McLaren PJ, Dorrell L, Shianna KV, Stemke A, Pelak K, et al. A genome-wide association study of resistance to HIV infection in highly exposed uninfected individuals with hemophilia A. Hum Mol Genet [Multicenter StudyResearch Support, N.I.H., Extramural Research Support, N.I.H., Intramural Research Support, U.S. Gov’t, P.H.S.] 2013 May 1;22(9):1903-10.

14. Tiret L, Rigat B, Visvikis S, Breda C, Corvol P, Cambien F, et al. Evidence, from combined segregation and linkage analysis, that a variant of the angiotensin I-converting enzyme (ACE) gene controls plasma ACE levels. Am J Hum Genet [Research Support, NonU.S. Gov’t] 1992 Jul;51(1):197-205.

15. Costerousse O, Allegrini J, Lopez M, Alhenc-Gelas F. Angiotensin I-converting enzyme in human circulating mononuclear cells: genetic polymorphism of expression in T-lymphocytes. Biochem J [Research Support, Non-U.S. Gov't] 1993 Feb 15;290 ( Pt 1):33-40.

16. Danser AH, Schalekamp MA, Bax WA, van den Brink AM, Saxena PR, Riegger GA, et al. Angiotensin-converting enzyme in the human heart. Effect of the deletion/insertion polymorphism. Circulation [Research Support, Non-U.S. Gov't] 1995 Sep 15;92(6):1387-8.

17. Puthucheary Z, Skipworth JR, Rawal J, Loosemore M, Van Someren K, Montgomery HE. The ACE gene and human performance: 12 years on. Sports Med 2011 Jun 1;41(6):433-48.

18. Harding D, Baines PB, Brull D, Vassiliou V, Ellis I, Hart A, et al. Severity of meningococcal disease in children and the angiotensinconverting enzyme insertion/deletion polymorphism. Am J Respir Crit Care Med [Research Support, Non-U.S. Gov't] 2002 Apr 15;165(8):1103-6.

19. Marshall RP, Webb S, Bellingan GJ, Montgomery HE, Chaudhari B, McAnulty RJ, et al. Angiotensin converting enzyme insertion/ deletion polymorphism is associated with susceptibility and outcome in acute respiratory distress syndrome. Am J Respir Crit Care Med [Comparative StudyResearch Support, Non-U.S. Gov't] 2002 Sep 1;166(5):646-50.

20. Hu Z, Jin X, Kang Y, Liu C, Zhou Y, Wu X, et al. Angiotensin-converting enzyme insertion/deletion polymorphism associated with acute respiratory distress syndrome among caucasians. J Int Med Res 2010 Mar-Apr;38(2):415-22.

21. Tsantes AE, Kopterides P, Bonovas S, Bagos P, Antonakos G, Nikolopoulos GK, et al. Effect of angiotensin converting enzyme gene I/D polymorphism and its expression on clinical outcome in acute respiratory distress syndrome. Minerva Anestesiol 2013 Aug;79(8):861-70.

22. Salnikova LE, Smelaya TV, Vesnina IN, Golubev AM, Moroz VV. Genetic susceptibility to nosocomial pneumonia, acute respiratory distress syndrome and poor outcome in patients at risk of critical illness. Inflammation [Research Support, Non-U.S. Gov't] 2014 Apr;37(2):295-305.

23. Rautanen A, Mills TC, Gordon AC, Hutton P, Steffens M, Nuamah R, et al. Genome-wide association study of survival from sepsis due to pneumonia: an observational cohort study. Lancet Respir Med [Observational Study Research Support, Non-U.S. Gov't] 2015 Jan;3(1):53-60. 